\title{
JARDIM, Denise F. 2017. Imigrantes ou refugiados? Tecnologias de controle e as fronteiras. Jundiaí: Paco Editorial. 256 p.
}

Gilmara Gomes da Silva Sarmento e Francilene dos Santos Rodrigues

\section{(2) OpenEdition Journals}

Edição electrónica

URL: http://journals.openedition.org/aa/4346

DOI: $10.4000 / a a .4346$

ISSN: 2357-738X

Editora

Programa de Pós-Graduação em Antropologia Social (UnB)

Edição impressa

Data de publição: 1 dezembro 2019

Paginação: 367-372

ISSN: 0102-4302

Refêrencia eletrónica

Gilmara Gomes da Silva Sarmento e Francilene dos Santos Rodrigues, «JARDIM, Denise F. 2017. Imigrantes ou refugiados? Tecnologias de controle e as fronteiras. Jundiaí: Paco Editorial. 256 p.», Anuário Antropológico [Online], v.44 n.2 | 2019, posto online no dia 03 dezembro 2019, consultado o 28 abril 2021. URL: http://journals.openedition.org/aa/4346 ; DOI: https://doi.org/10.4000/aa.4346

\section{(c) (i) (9)}

Anuário Antropológico is licensed under a Creative Commons Atribuição-Uso Não-Comercial-Proibição de realização de Obras Derivadas 4.0 International. 


\section{JARDIM, Denise F. 2017. Imigrantes ou refugiados? Tecnologias de controle e as fronteiras. Jundiaí: Paco Editorial. 256 p.}

Gilmara Gomes da Silva Sarmento Universidade Federal de Roraima - Brasil

Francilene dos Santos Rodrigues Universidade Federal de Roraima - Brasil

"Imigrantes ou refugiados? Tecnologias de controle e as fronteiras" é uma descrição densa sobre as tecnologias da governamentalidade voltadas para as migrações. Ao tomar essa questão como objeto de análise, Denise Fagundes Jardim expõe de maneira pormenorizada os diferentes aspectos que configuram essas tecnologias de poder, a saber, suas materialidades, suas dinâmicas e seus agentes. O livro é uma referência importante não apenas por destrinchar toda engrenagem que encarna e opera a governamentalidade das migrações, mas especialmente, por evidenciar como essas tecnologias de controle se impõem aos corpos, às vidas e ao itinerário de imigrantes e refugiados.

A pertinência do livro não se esgota nas diferentes chaves de leitura propostas para pensar o fenômeno migratório, mas se estende também ao recorte teórico-metodológico empregado na construção do objeto de análise aqui referenciado. Segundo a expressão da própria autora, o livro resulta de uma "antropologia participativa” tecida a partir das múltiplas experiências e entradas no tema das imigrações internacionais como professora/pesquisadora, mas também da militância como antropóloga no tema dos direitos humanos. Ao apresentar uma análise dessas experiências, Denise Jardim nos brinda com informações valiosas apreendidas através da pesquisa etnográfica, junto a três perfis distintos de migrantes e a partir de outros lugares de observação, de escuta e de interlocução, quando interpelada pelo tema das migrações. Entretanto, suas reflexões vão além dessas fontes de pesquisa, pois o escrutínio de documentos, tratados e dispositivos, produzidos e exigidos no âmbito da governamentalidade das migrações, também foi uma atividade de pesquisa importante que permitiu à autora confrontar as limitações entre discursos e as práticas sociais.

O itinerário dos imigrantes examinado à luz de um conjunto de exigências, de 
protocolos, de burocracias e de formas de atuação, às vezes controversas, de agentes estatais (e não estatais) contradiziam as referências a favor das tecnologias de controle como facilitadoras da migração. Ao contrário desse argumento, o estudo empreendido por Jardim mostra como essas tecnologias, em realidade, produzem inúmeras barreiras, dilemas e dramas que marcam a biografia daqueles(as) que, por distintas razões, ultrapassam os limites de estados nacionais para [re]fazer a vida. E, ainda, como os percalços que surgem no decorrer desse processo alteram os "fluxos de vida" dessas pessoas.

De acordo com a autora, esses paradoxos evidenciam também a debilidade das instituições, do aparato burocrático e das lógicas de atendimento no país de "acolhida”, pondo em xeque as incongruências entre os compromissos assumidos em convenções internacionais e o tratamento dado aos imigrantes e às suas demandas. Nesse sentido, a obra é reveladora, ao assinalar que conhecer o itinerário de imigrantes significa acessar também aspectos profundos da sociedade destino às vezes dissimulados na imagem de uma sociedade "que acolhe".

O livro está dividido em duas partes independentes, porém complementares. Na primeira parte da obra, o(a) leitor(a) vai encontrar uma descrição detalhada das tecnologias da governamentalidade da imigração, definidas pela autora, inspirada em Michel Foucault, como todas as demandas produzidas no âmbito estatal, ainda que por agentes não governamentais, cujo intuito é gestar a vida de determinados grupos e o controle populacional. Nos três capítulos que compõem essa parte do livro, a autora expõe, de forma subsequente, essas tecnologias da governamentalidade, a partir de três eixos: as materialidades, suas dinâmicas e seus agentes.

As materialidades, trabalhadas no Capítulo 1, encarnam os processos burocráticos de identificação, registros, contabilizações, confecções de documentos e exigências de inúmeros papéis mediados por lógicas jurídico-administrativas cambiantes que se impõem aos imigrantes, e sobre as quais esses sujeitos são convocados a aprender articular no transcurso do seu itinerário migratório. No Capítulo 2, a autora analisa os dispositivos da governamentalidade materializados em leis, cartas e convenções internacionais e a sua historicidade, observando como essas ferramentas jurídicas são manejadas e modelam lógicas administrativas que requerem dos sujeitos migrantes a capacidade para decifrar, aceitar e confiar nessas tecnologias da governamentalidade, a priori, conduzidas por mecanismos legais. No Capítulo 3, a autora apresenta os distintos agentes da governamentalidade, estatais e da sociedade civil, atores que atuam e conformam uma rede de interlocução sobre temas como 
imigração, refúgio e direitos humanos, e que, inseridos em ações de mediação das resoluções das demandas dos imigrantes, presentificam dificuldades burocráticas, tensões e negociações de sentido.

Na segunda parte da obra, o foco recai sobre os "fluxos de vida" dos sujeitos definidos ou categorizados como imigrantes ou refugiados, segundo determinada lógica jurídico-administrativa, e como as inúmeras requisições geradas pelas tecnologias de controle afetam a vida dessas pessoas, ordenando e redefinindo a imigração. Cada um dos três capítulos que compõem essa parte do livro refere-se a contextos de pesquisa diferentes.

No capítulo 4, a experiência migratória de palestinos no sul do país permite expor o jogo de forças e disputas de sentido que se impõem ao fluxo de vida de imigrantes categorizados como refugiados, possibilitando relativizar o discurso hegemônico sobre proteção humanitária. Desvela como a eleição do dispositivo humanitário do refúgio, anunciado como uma vantagem jurídica, pode, dependendo das conjunturas políticas e de suas lógicas institucionais, excluir, inviabilizar e restringir o curso de vida das pessoas e, ao mesmo tempo, como alguma expertise sobre os percalços e as incertezas inerentes a esses legalismos, resultar na recusa de acionar esse dispositivo pelos imigrantes. Afinal de contas, sob essas condições "quem quer ser um refugiado?”, como questiona a própria autora em alusão ao filme Quem quer ser um milionário? (dirigido por Danny Boyle e lançado em 2008).

O capítulo 5 descreve e problematiza os entraves ao acesso de haitianas grávidas a hospitais e postos de saúde do sistema público no sul do país. O dilema dessas mulheres revelou que os obstáculos impostos aos imigrantes transcende a sua condição de regular. Embora portadoras de documentos (agilizados com base na Lei do Refúgio), essas mulheres eram recebidas como "estrangeiras" pelos agentes do serviço público, numa lógica de negação de direitos que se materializava em emperramentos burocráticos no acesso aos serviços de saúde. Ao descrever o itinerário dessas imigrantes, o capítulo revela também fragilidades e zonas de invisibilidade, de abandono e de exclusão constitutivos do sistema de governabilidade e de suas lógicas de funcionamento (formas de abordagem, elegibilidade e as prioridades).

O sexto e último capítulo expõe a experiência de mulheres equatorianas inseridas no trabalho doméstico na Espanha e, por consequência, os paradoxos da regularização como um contínuo dramático de conexões entre aprendizados sobre as rotinas burocráticas e a busca por regularização e por direitos. Além dos esforços para inserção laboral na sociedade de acolhida para reunificar a vida da família frag- 
mentada pelo processo migratório, este capítulo aborda, ainda, as estratégias de resposta ou de submissão dessas migrantes diante das novas formas de disciplinamentos sobre os corpos migrantes e dos constrangimentos legais e morais resultantes dessa condição.

Finalmente, os novos horizontes interpretativos, fornecidos pelo livro, para pensar o fluxo migratório, o torna uma leitura fundamental, especialmente para acadêmicos, militantes e demais agentes envolvidos com o tema das migrações e dos direitos humanos. É um livro que interroga as categorias produzidas no âmbito da governamentalidade das migrações, colocando em evidência a fragilidade de pressupostos sociais muitas vezes ratificados por abordagens acadêmicas que lidam com o fenômeno migratório como "um problema social" e o migrante como um necessitado de integração.

Ao tomar a migração sob a ótica dos direitos, e a voz (experiência/trajetória) dos migrantes como centro da análise, Denise Fagundes Jardim traz à baila uma série de problemáticas relacionadas ao dispositivo do refúgio e explicita que embora concebido e autoproclamado como uma solução para situações específicas de deslocamento, quando analisado a partir das situações concretas de acionamento, esse dispositivo não passa de outra tecnologia de seletividade que depende do "jogo social e político" e "das negociações entre partes com poderes desiguais" (p. 243) e, portanto, restringe a circulação e à vida das pessoas categorizadas como refugiadas. Essas limitações, explicam, por exemplo, por que imigrantes que em tese possuíam os critérios para pleitear o refúgio se recusavam a acioná-los, respondendo, portanto, à indagação inicial da autora: imigrantes ou refugiados?

Recebido: 02/10/2018

Aprovado: 15/01/2019

Gilmara Gomes da Silva Sarmento é cientista social. Doutorado em Ciências Sociais pelo Programa de Ciências Sociais em Desenvolvimento, Agricultura e Sociedade. Pós-doutoranda no Programa de Pós-Graduação Sociedade e Fronteiras (PNPD/CAPES/UFRR). ORCID: 0000-0001-6583-4477. Contato: gilmarasarmento@hotmail.com 
Francilene dos Santos Rodrigues tem Pós-doutorado em Gênero, Identidade e Cidadania, pela Universidade de Huelva-Espanha; Doutorado em Ciências Sociais, pelo Centro de Estudos Comparados das Américas (CEPPAC), da Universidade de Brasília; Mestrado em Desenvolvimento Sustentável do Trópico Úmido (PPGDTU), pela Universidade Federal do Pará. Atualmente é docente da Universidade Federal de Roraima e participa, como docente permanente, nos programas de Pós-graduação em Recursos Naturais (PRONAT) e Sociedade e Fronteiras (PPGSOF), do qual foi coordenadora. É líder do GEIFRON-Grupo de Estudos Interdisciplinar sobre Fronteiras e coordena a Linha de Pesquisa: Migração, Gênero e Violência. https://orcid.org/0000-0003-1618-3684. Contato: france.rodrigues@ufrr.com.br 